\title{
Increased plasma levels of interleukin-1, interleukin-6 and $\alpha$-1-antichymotrypsin in patients with Alzheimer's disease: peripheral inflammation or signals from the brain?
}

\author{
Federico Licastro ${ }^{\mathrm{a}, *}$, Steve Pedrini ${ }^{\text {a }}$, Ludovica Caputo ${ }^{\mathrm{b}}$, Giorgio Annoni ${ }^{\mathrm{b}}$, \\ Lizabeth Jane Davis ${ }^{a}$, Cinzia Ferri ${ }^{c}$, Valeria Casadei ${ }^{c}$, Luigi Maria Edoardo Grimaldi ${ }^{c}$ \\ ${ }^{a}$ Department of Experimental Pathology, University of Bologna, Via S. Giacomo 14, 40126 Bologna, Italy \\ ${ }^{\mathrm{b}}$ Geriatric Clinics, University of Milano and Ospedale Maggiore IRCCS, Milan, Italy \\ ${ }^{c}$ Department of Neurology, DIBIT, San Raffaele Hospital, University of Milan, Milan, Italy
}

Accepted 6 October 1999

\begin{abstract}
Plasma concentrations of interleukin-1 $\beta$ (IL-1 $\beta$ ), interleukin-6 (IL-6), C reactive protein (CRP) and $\alpha-1$-antichymotrypsin (ACT) in 145 patients with probable Alzheimer's disease (AD) and 51 non-demented controls were measured. To investigate the cellular activation of peripheral immune system, plasma levels of neopterin were also investigated. Plasma levels of IL-1 were detectable in 17 patients with $\mathrm{AD}(13 \%)$ and only in one control (2\%) and average levels of IL-1 were higher in AD patients than in controls $(p<0.001)$. IL-6 plasma levels were detectable in a higher proportion of $\mathrm{AD}$ and controls (53\% and 27\%, respectively), and were increased in patients with $\mathrm{AD}$ $(p<0.001)$. Plasma levels of ACT were increased in patients with AD $(p<0.001)$ and CRP levels were in the normal range. Plasma levels of neopterin were slightly lower in AD patients than in controls, but differences were not statistically significant. No significant correlation was observed between IL-1 and IL-6 levels or neopterin and cytokine levels in plasma from AD patients. Plasma levels of ACT negatively correlated with cognitive performances, as assessed by the mini mental state examination (MMSE; $R=-0.26$, $p<0.02)$ and positively correlated with the global deterioration state (GDS) of AD patients $(R=0.30, p<0.007)$. Present findings suggested that detectable levels of circulating cytokines and increased ACT might not be derived by activation of peripheral immune system of AD patients. Detection of these molecules might be used for monitoring the progression of brain inflammation associated with AD. (C) 2000 Published by Elsevier Science B.V. All rights reserved.
\end{abstract}

Keywords: Alzheimer's disease; Plasma IL-1; IL-6; ACT; Cognitive impairment

\section{Introduction}

Cytokines are molecules secreted by cells of the immune system and other organs with multiple regulatory roles (Kelso, 1998). Interleukin (IL)-1 and IL-6 show both paracrine activity on local tissue immune responses and endocrine activity on other organs and systems, such as the brain and liver (Gauldie et al., 1992; Dinarello, 1998). Both cytokines activate the synthesis and secretion of

\footnotetext{
"Corresponding author. Tel.: +0039-51-2094730; fax: +0039-512094746; e-mail: licastro@alma.unibo.it
}

acute phase proteins by the liver during acute or chronic inflammation (Travis and Salvelsen, 1983; Baumann and Gauldie, 1994; Dinarello, 1998).

IL-1 is secreted by activated microglia and most microglia surrounding neuro-pathological lesions of $\mathrm{AD}$ brains are immunopositive for IL-1 (Griffin et al., 1989). Moreover, the distribution of IL-1 positive microglia cells correlated with the distribution of amyloid plaques in $\mathrm{AD}$ brains (Sheng et al., 1998).

IL-6 is also over-expressed in the brain of patients with AD (Bauer et al., 1991; Strauss et al., 1992). It is of interest that IL-6 appeared to be linked to early stages of plaque formation (Huell et al., 1995). The above findings contributed to the notion that cytokines appeared to play a 
primary role in inflammation associated with chronic degenerative alterations of the AD brain (Griffin et al., 1998; McGeer and McGeer, 1998).

Increased blood levels of IL-1 $\beta$ has been found in patients with late onset AD (Alvarez et al., 1996) and altered peripheral levels of IL-6 have been reported during aging and in patients with Alzheimer's disease (Licastro et al., 1995a; Kalman et al., 1997; Singh and Guthikonda, 1997; Bonaccorso et al., 1998). However, other investigations failed to confirm an increase of IL-6 blood levels in AD (Van Duijn et al., 1990; Angelis et al., 1998).

ACT is a protease inhibitor and an acute phase reactant (Travis and Salvelsen, 1983). This serpin is a secondary component of amyloid deposits in AD brains (Abraham et al., 1988, 1990), binds $A \beta$-peptides and affects the rate of amyloid fibril formation in vitro (Fraser et al., 1993; Ma et al., 1994; Eriksson et al., 1995). IL-1, IL-6 and ACT might be functionally linked in brain cells, since these cytokines induced the expression of ACT in human astrocytoma cell lines (Lieb et al., 1996) or human cortical astrocytes (Kordula et al., 1998). Increased levels of ACT were also found in brain samples from AD patients (Abraham et al., 1990; Licastro et al., 1998).

Serological studies on ACT have shown that increased serum levels were associated with AD (Licastro et al., 1995a,b), while serum levels of other acute phase reactants such as $\alpha$-1-antitrypsin, $\alpha$-2-macroglobulin or $\alpha$-1-acidic protein were not increased (Licastro et al., 1995b). Elevated levels of serum ACT have also been reported in a subset of first degree relatives of AD patients (Altstiel et al., 1995). However, other studies reported normal levels of ACT from peripheral blood of AD patients (Furby et al., 1991; Kuiper et al., 1993; Pirttila et al., 1994).

The increase of some cytokines and acute phase reactants in the blood of AD patients has suggested the possible presence of a systemic chronic inflammation associated with the disease. However, circulating IL-1 $\beta$ or IL-6 are often undetectable or within normal range (Van Duijn et al., 1990; Angelis et al., 1998) in many patients with AD and this argues against the presence of a classical generalized inflammation in AD. Furthermore, cytokine network is complex and these molecules are biologically labile and rapidly disappear from the circulation.

An indirect approach to monitor peripheral immune responses is to detect stable metabolites derived by the activation of immune system cells, such as neopterin (Fuchs et al., 1993). Neopterin derives from guanosine triphosphate and activated monocytes released high levels of this metabolite (Fuchs et al., 1993). Recently, increased neopterin levels have been found in patients with AD (Leblhuber et al., 1999).

In the present study, we have concomitantly measured IL-1 $\beta$, IL-6, ACT and neopterin blood levels from a large sample of patients with probable AD and healthy elderly. Our findings do not support the notion of a peripheral activation of the immune system in these patients.

\section{Material and methods}

\subsection{Patients and controls}

The present study was carried out on 145 patients with probable AD and 51 non-demented subjects selected from the Neurology Department of the San Raffaele Hospital and the Geriatric Department, University of Milan, Italy. Clinical diagnosis of $\mathrm{AD}$ was performed according with the criteria of the DMS III-R and NINCDS-ADRDA (Mackhann et al., 1984). AD patients and controls were living at home, they were physical examined on the day of blood collection and their clinical records evaluated. In order to minimize the risk of clinical or sub-clinical inflammatory processes, both controls and AD patients were selected as follows. Only AD patients and controls without clinical sign of inflammation (e.g., normal body temperature or absence of concomitant inflammatory disease) were selected for this study. Blood chemical parameters were also evaluated and patients or controls with abnormal sedimentation rate of red blood cells or altered blood profile of albumin and transferrin plasma levels were not included. A further selection of AD patients were performed according the $\mathrm{C}$ reactive protein (CRP) plasma levels and those patients with CRP above $5 \mathrm{mg} / 1$ (mean value \pm 2 standard deviations of control values) were not included in the study. Informed consent to perform the study was obtained from controls and a relative of each AD patient.

\subsection{Blood cytokines, acute phase proteins and neopterin}

Blood levels of IL-1 $\beta$ and IL-6 were measured by commercially available enzyme linked immunoassays (Endogen, Italy and PKL, Germany).

Levels of ACT and CRP were measured by a radial immunodiffusion kit (NANORID; the Binding Site, UK), as previously described (Licastro et al., 1998). Circulating levels of neopterin were also measured by ELISA kit (PKL).

Plasma proteins were assessed as described elsewhere (Lowry et al., 1951) with slight modifications.

\subsection{Statistical comparisons}

Statistical comparisons between the mean values of different variables from $\mathrm{AD}$ and controls were performed by the two tailed Student's $t$-test using a computerized statistical program (Stat View, USA). The degree of correlation between different variables was assessed by linear regression analysis and the regression coefficients were calculated by a computerized statistical program (Stat View).

\section{Results}

Age, gender, and MMSE scores from controls and AD patients are reported in Table 1. The degree of cognitive 
Table 1

Clinical features of non-demented controls and patients with AD. Cognitive performances were assessed by the MMSE and GDS

Data are shown as mean \pm S.E.

\begin{tabular}{lrllll}
\hline & \multicolumn{1}{c}{$n$} & Age & Gender & MMSE & GDS \\
\hline Controls & 51 & $78 \pm 2$ & $31 \mathrm{~F} / 20 \mathrm{M}$ & $>26$ & - \\
AD & 145 & $75 \pm 1$ & $91 \mathrm{~F} / 54 \mathrm{M}$ & $15 \pm 1$ & $4.5 \pm 0.1$ \\
\hline
\end{tabular}

deterioration of $\mathrm{AD}$ patients according the global deterioration state (GDS) has also been evaluated and included in the table.

Circulating levels of IL-1 $\beta$ were higher in patients with $\mathrm{AD}(p<0.001)$ than in controls (Fig. 1, panel A). This cytokine was detectable only in one healthy elderly $(2 \%)$ and in $17 \mathrm{AD}$ patients (13\%). Plasma levels of IL-6 were increased $(p<0.001)$ in patients with $\mathrm{AD}$ (Fig. 1, panel B). The frequency of IL-6 positivity was higher than that of IL-1 $\beta$ in both controls and AD, and $27 \%$ of elderly controls and 53\% of AD patients showed detectable levels of this cytokine. No statistical significant correlation was observed between plasma IL- $1 \beta$ and IL-6 (regression coefficient, $R=-0.10, p=0.37$ ). The analysis was then restricted to $\mathrm{AD}$ patients who were concomitantly positive for IL-1 $\beta$ and IL-6; once again, no significant correlation between plasma levels of the two cytokines was observed $(R=-0.13, p=0.61)$.

Levels of blood ACT in non-demented controls and AD patients are shown in Fig. 2 (panel A). Circulating ACT levels were expressed as percentage of total proteins and were increased in $\mathrm{AD}(p<0.001)$. No difference in plasma levels of CRP between controls and AD $(1.2 \pm 0.2 \mathrm{mg} / 1$ and $1.8 \pm 0.3 \mathrm{mg} / 1$, respectively) was observed. No significant correlation between either plasma levels of ACT and CRP or between cytokine levels and circulating ACT or CRP was present (data not shown).
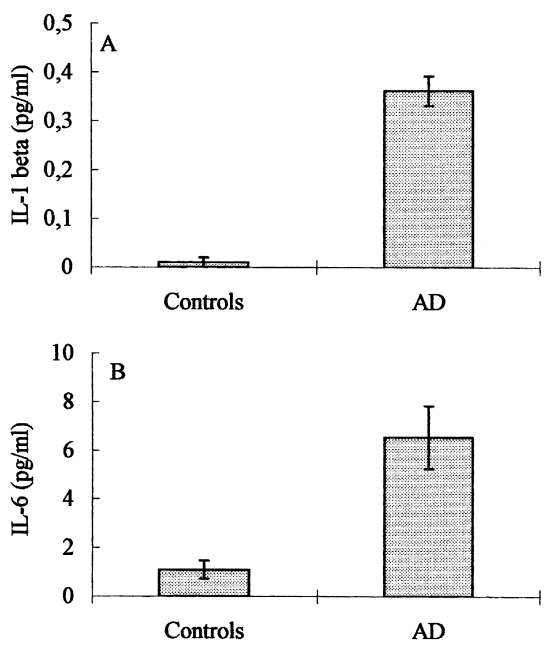

Fig. 1. Plasma levels of IL-1 $\beta$ (panel A) and IL-6 (panel B) in non-demented controls and patients with probable AD.
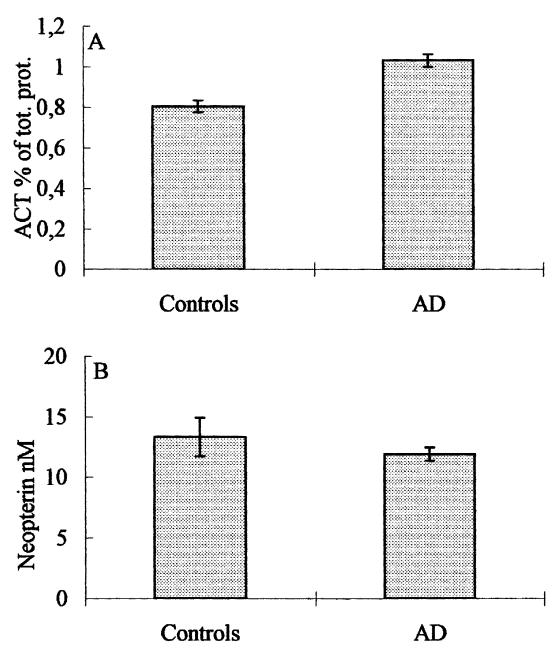

Fig. 2. Plasma levels of ACT (panel A) and neopterin (panel B) in non-demented controls and patients with probable AD.

Circulating levels of neopterin were slightly lower in $\mathrm{AD}$ patients than in controls (Fig. 2, panel B), but the difference was not statistically significant.

Circulating ACT appeared to be affected by cognitive performances in patients with $\mathrm{AD}$, since plasma ACT negatively correlated with MMSE $(R=-0.26, p=0.02$; Fig. 3, panel A) and positively correlated with GDS ( $R=$ 0.30, $p=0.006$; Fig. 3, panel B).
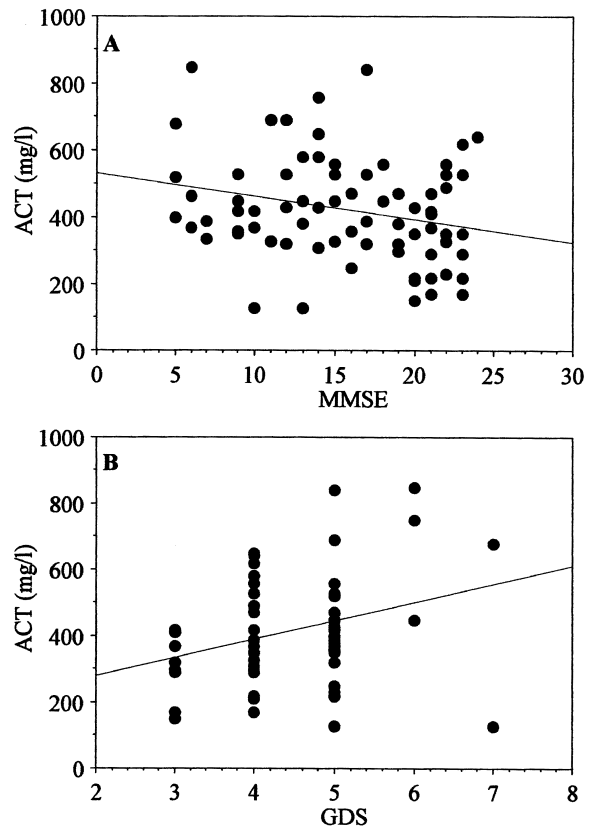

Fig. 3. Linear regression analysis between ACT levels and MMSE scores in patients with $\mathrm{AD}(R=-0.26, p=0.02$; panel $\mathrm{A})$. Linear regression analysis between ACT levels and GDS scores in patients with AD $(R=0.30, p=0.006$; panel B). 


\section{Discussion}

Epidemiological studies showed that the routine use of non-steroid anti-inflammatory drugs was associated with a decreased incidence of $\mathrm{AD}$ in a co-twin control study (Breitner et al., 1994). A statistical meta-analysis of 17 epidemiologic studies confirmed a decreased association of $\mathrm{AD}$ in individuals exposed to arthritis or anti-inflammatory drugs (McGeer et al., 1996). Activated microglia, over-expression of cytokines and other inflammatory molecules are common features of the AD brain pathology (Mrak et al., 1995). All together, these findings have led to the hypothesis that inflammation might contribute to the neuro-degeneration associated with $\mathrm{AD}$ (McGeer et al., 1996).

Altered systemic or peripheral immune mechanisms (Licastro et al., 1995a,b; Alvarez et al., 1996; Kalman et al., 1997; Singh and Guthikonda, 1997; Bonaccorso et al., 1998) are also observable in a variable proportion of patients with $\mathrm{AD}$. These results have suggested that a generalized chronic inflammation might be associated with AD.

Data presented here showed that AD patients had increased blood levels of IL-1 $\beta$, IL- 6 and ACT and were in accordance with findings from previous reports (Licastro et al., 1995a,b, 1999).

However, no clinical signs of systemic inflammation, such as elevated temperature or increased erythrocyte sedimentation rate were present in these patients. Moreover, serum levels of another acute phase reactant, CRP, were low and did not differ between AD and controls. Therefore, the meaning of increased levels of selected molecules with immune-regulatory functions in the peripheral blood of patients with $\mathrm{AD}$ still remained obscure.

To further investigate markers of the peripheral immune system activation, we measured the circulating levels of neopterin. This metabolite is generated by GTP-cyclohydrolase and the activity of the enzyme and neopterine production are increased under cytokine activation of the reticulo-endothelial cell system (Fuchs et al., 1993). Neopterin is stable, concentrations of this compound reflect the activity of the cell-mediated immune response and increased circulating levels of neopterin are associated with infectious or autoimmune diseases (Fuchs et al., 1993). Recently, increased blood levels of neopterin have been found in a small sample of patients with AD (Leblhuber et al., 1999).

Our findings showed that circulating levels of neopterin were within the normal range in patients with $\mathrm{AD}$ and did not support the above observation (Leblhuber et al., 1999). Neopterin levels were not altered even in AD patients with increased IL-1 $\beta$ or IL- 6 blood levels. Discrepancies with the above report might be ascribed to a different selection of $\mathrm{AD}$ patients. For instance, both $\mathrm{AD}$ and controls from the present study did not show subclinical or laboratory signs of systemic inflammation and were older than those investigated by the other group (Leblhuber et al., 1999). Our results suggested that the mild, but significant, increment of IL-1 $\beta$ and IL-6 levels in patients with AD could not be secondary to a peripheral immune response. On the other hand, previous investigations have shown that serum levels of other acute phase proteins were not altered in patients with $\mathrm{AD}$, even in those patients showing increased levels of IL-6 or ACT (Licastro et al., 1995a, 1999).

It has been shown that brain microvessel endothelium cells synthesized and released IL-1 and IL-6 (Fabry et al., 1993). Endothelial cells were also able to release ACT (Papadimitriou et al., 1980). Therefore, these molecules might also derive from activated endothelia of brain vessels, as a consequence of inflammatory processes in the central nervous system (CNS). It is of interest that the activation of the inflammatory response in the CNS of rats by intra-cerebroventricular injection of IL-1 $\beta$ resulted in increased serum IL-6 (De Simoni et al., 1993). Recently, intracerebroventricular injection of IL-1 $\beta$ resulted in increased IL-6 levels in the CSF and blood from a primate animal model (Xiao et al., 1999). Furthermore, It has been shown that both IL- $1 \beta$ and IL- 6 could induce ACT release from human astrocytes (Lieb et al., 1996; Kordula et al., 1998). Therefore, increased peripheral ACT levels might also be secondary to inflammatory events in the CNS of AD.

In $\mathrm{AD}$ patients, levels of circulating ACT correlated with the cognitive performances, as assessed by both MMSE or GDS. These findings paralleled other data from a prospective study showing that ACT serum levels were increased in very old subjects and correlated with the cognitive impairment in an elderly population without AD (Gabriel et al., 1998). Our findings suggested that ACT might be an important factor associated with brain functioning in the elderly. For instance, this serpin bind A $\beta$ peptides and increased the amyloid deposition (Fraser et al., 1993; Ma et al., 1994; Eriksson et al., 1995). More recently, it has been shown that ACT inhibited a metalloendopeptidase involved in $\mathrm{A} \beta$-peptide degradation (Yamin et al., 1999).

In conclusion, data presented here suggested that the modest increase of circulating IL-1, IL-6 and ACT molecules might be secondary to brain alterations associated with of $\mathrm{AD}$ and these compounds might be metabolically linked with other mechanisms controlling neuro-degeneration of CNS. Longitudinal assessment of these molecules from the peripheral blood might also be useful to monitor the effects of anti-inflammatory therapies in patients with AD.

\section{Acknowledgements}

Research partially supported by Italian MURST $40 \%$ and $60 \%$ and ARAD, Italy. 


\section{References}

Abraham, C.R., Selkoe, D.J., Potter, H., 1988. Immunochemical identification of the serine protease inhibitor, alpha-1-antichymotrypsin in the brain amyloid deposits. Cell 52, 487-501.

Abraham, C.R., Shirahama, T., Potter, H., 1990. Alpha-1-antichymotrypsin is associated solely with amyloid deposits containing the $\beta$-protein. Amyloid and cell localization of alpha-1-antichymotrypsin. Neurobiol. Aging 1, 123-129.

Altstiel, L.D., Lawlor, B., Mohs, R., Schmeidler, J., Dalton, A., Metha, P., Davis, K., 1995. Elevated alpha-1-antichymotrypsin serum levels in a subset of non-demented first-degree relatives of Alzheimer's disease patients. Dementia 6, 17-20.

Alvarez, X.A., Franco, A., Fernandez-Novoa, F., Cacabelos, R., 1996. Blood levels of histamine, IL-1 beta and TNF-alpha in patients with mild to moderate Alzheimer disease. Mol. Chem. Neuropathol. 29, 237-252.

Angelis, P., Sharf, S., Mander, A., Vajda, F., Christophidis, N., 1998. Serum interleukin-6 and interleukin-6 soluble receptor in Alzheimer's disease. Neurosci. Lett. 244, 106-108.

Bauer, J., Strauss, S., Schreiter-Gasser, U., Genter, U., Schlegel, P., Witt, I., Volk, B., Berger, M., 1991. Interleukin-6 and $\alpha$-2-macroglobulin indicate an acute phase state in Alzheimer's disease cortex. FEBS Lett. 285, 111-114.

Baumann, H., Gauldie, J., 1994. The acute phase response. Immunol. Today $15,74-80$.

Bonaccorso, S., Lin, A., Song, C., Verkerk, R., Kenis, G., Bosmans, E., Scharpe, S., Vandewoude, M., Dossche, A., Maes, M., 1998. Serotonine-immune interactions in elderly volunteers and in patients with Alzheimer's disease (DAT): lower plasma tryptophan availability to the brain in the elderly and increased serum interleukin-6 in DAT. Aging (Milano) 10, 316-323.

Breitner, J.C.S., Gau, B.A., Welsh, K.A., Plassman, B. L, McDonald, W.M., Helms, M.J., Anthony, J.C., 1994. Inverse association of anti-inflammatory treatments and Alzheimer's disease. Neurology 44, 227-232.

De Simoni, M.G., De Luigi, A., Gemma, L., Sironi, M., Manfridi, A., Ghezzi, P., 1993. Modulation of systemic interleukin-6 induction by central interleukin-1. Am. J. Physiol. 265, R739-R742.

Dinarello, C.A., 1998. Interleukin-1, Interleukin-1 receptors and Interleukin-1 receptor antagonist. Int. Rev. Immunol. 16, 457-499.

Eriksson, S., Janciauskiene, S., Lannfelt, L., 1995. Alpha-1-antichymotrypsin regulates Alzheimer $\beta$-amyloid peptide fibril formation Proc. Natl. Acad. Sci. U.S.A. 92, 2313-2317.

Fabry, Z., Fitzsimmons, K.M., Herlein, J.A., Moninger, T.O., Dobbs, M.B., Hart, M.N., 1993. Production of the cytokines interleukin-1 and -6 by murine brain microvessel endothelium and smooth muscle pericytes. J. Neuroimmunol. 47, 23-34.

Fraser, P.E., Nguyen, J.T., McLachlan, D.R., Abraham, C.R., Kirschner, D.A., 1993. Alpha-1-antichymotrypsin binding to Alzheimer A $\beta$ peptides is sequence specific and induces fibril disaggregation in vitro. $\mathrm{J}$. Neurochem. 6, 298-305.

Fuchs, D., Weiss, G., Wachter, H., 1993. Neopterin, biochemistry and clinical use as a marker for cellular immune reactions. Int. Arch. Allergy Immunol. 101, 1-6.

Furby, A., Leys, D., Delacourte, A., Buee, L., Soetaert, G., Petit, H., 1991. Are alpha-1-antichymotrypsin and inter-alpha-trypsin inhibitor peripheral markers of Alzheimer's disease?. J. Neurol., Neurosurg. Psychiatry 54, 469.

Gabriel, S.M., Marin, D.B., Aisen, P.S., Lantz, M., Altstiel, L.D., Davis, K.L., Mohs, C.R., 1998. Association of elevated $\alpha$-1-antichymotrypsin with cognitive impairment in a prospective study of the very old. Am. J. Psychiatry 155, 698-700.

Gauldie, J., Richards, C., Baumann, H., 1992. IL-6 and the acute phase reaction. Res. Immunol. 143, 755-759

Griffin, W., Stanley, L.C., Ling, C., White, L., MacLeod, V., Perrot, L.J., White, C.L. III, Araoz, C., 1989. Brain interleukin-1 and S-100 immunoreactivity elevated in Down's syndrome and Alzheiemer's disease. Proc. Natl. Acad. Sci. U.S.A. 86, 7611-7615.

Griffin, W.S., Sheng, J.G., Royston, M.C., Gentleman, S.M., McKenzie, J.E., Graham, D.I., Roberts, G.W., Mrak, R.E., 1998. Glial-neuronal interactions in Alzheimer's disease: the potential role of a 'cytokine cycle' in disease progression. Brain Pathol. 8, 65-72.

Huell, M., Strauss, S., Volk, B., Berger, M., Bauer, J., 1995. Interleukin-6 is present in early stages of plaque formation and is restricted to the brain of Alzheimer's disease patients. Acta Neuropathol. 89, 544-551.

Kalman, J., Juhasz, A., Laird, G., Dickens, P., Jardanhazy, T., Rimanoczy, A., Boncz, I., Parry-Jones, W.L., Janka, Z., 1997. Serum interleukin-6 levels correlate with the severity of the dementia in Down's syndrome and Alzheimer's disease. Acta Neurol. Scand. 96, 236-240.

Kelso, A., 1998. Cytokines: principles and prospects. Immunol. Cell Biol. 76, 300-317.

Kordula, T., Rydel, R.E., Brigham, E.F., Horn, F., Heinrich, P.C., Travis, J., 1998. Oncostatin M and the interleukin-6 and soluble interleukin-6 receptor complex regulate alpha-1-antichymotrypsin expression in human cortical astrocytes. J. Biol. Chem. 237, 4112-4118.

Kuiper, M.A., van-Kamp, G.J., Bergmans, P.L., Scheltens, P., Wolters, E.C., 1993. Serum alpha-1-antichymotrypsin is not a useful marker for Alzheimer's disease or dementia in Parkinson's disease. J. Neural Transm.: Parkinson's Dis. Dement. Sect. 6, 145-149.

Leblhuber, F., Walli, J., Demel, U., Tilz, G.P., Winder, B., Fuchs, D., 1999. Increased serum neopterin concentrations in patients with Alzheimer's disease. Clin. Chem. Lab. Med. 37, 429-431.

Licastro, F., Morini, M.C., Polazzi, E., Davis, L.J., 1995a. Increased serum alpha-1-antichymotrypsin in patients with probable Alzheimer's disease: an acute phase reactant without the peripheral acute phase response. J. Neuroimmunol. 57, 71-75.

Licastro, F., Parnetti, L., Morini, M.C., Davis, L.J., Cucinotta, D., Gaiti, A., Senin, U., 1995b. Acute phase reactant alpha-1-antichymotrypsin is increased in cerebrospinal fluid and serum of patients with probable Alzheimer's disease. Alzheimer Dis. Assoc. Disorder. 9, 112-118.

Licastro, F., Mallory, M., Hansen, L.A., Malsiah, E., 1998. Increased levels of $\alpha$-1-antichymotrypsin in brains of patients with Alzheimer's disease correlate with activated astrocytes and are affected by APOE 4 genotype. J. Neuroimmunol. 88, 105-110.

Licastro, F., Masliah, E., Pedrini, S., Thal, L.J., 1999. Blood levels of $\alpha$-1-antichymotrypsin and risk factor for Alzheimer's disease: effects of gender and apolipoprotein E genotype. Dementia Geriatr. Cognit. Disord. 633, in press.

Lieb, K., Fiebich, B.L., Schaller, H., Berger, M., Bauer, J., 1996. Interleukin-1 beta and tumor necrosis factor-alpha induce expression of alpha-1-antichymotrypsin in human astrocytoma cells by activation of nuclear factor-kappa B. J. Neurochem. 67, 2039-2044.

Lowry, O.H., Rosenburg, N.J., Farr, A.L., Randall, R.J., 1951. Protein measurement with the folin phenol agent. J. Biol. Chem. 193, 265275.

Ma, J., Yee, A., Brewer, H.B., Das, S., Potter, H., 1994. Amyloid-associated proteins alpha-1-antichymotrypsin and apolipoprotein E promote assembly of Alzheimer $\beta$-protein into filaments. Nature 372, 92-94.

Mackhann, G., Drachman, D., Folstein, M., Katzman, R., Proce, D., Stadlan, E.M., 1984. Clinical diagnosis of Alzheimer's disease. Neurology 34, 939-944.

McGeer, E.G., McGeer, P.L., 1998. The importance of inflammatory mechanisms in Alzheimer's disease. Exp. Gerontol. 33, 371-378.

McGeer, P.L., Schulzer, M., McGeer, E.G., 1996. Arthritis and anti-inflammatory agents as possible protective factors for Alzheimer's disease: a review of 17 epidemiological studies. Neurology 47, 425432.

Mrak, R.E., Sheng, J.G., Griffin, S.T., 1995. Glial cytokines in Alzheimer's disease: review and pathogenetic implications. Hum. Pathol. 26, 816-823.

Papadimitriou, C.S., Stein, H., Papacharalampous, N.X., 1980. Presence of $\alpha$-1-antichymotrypsin in hemopoietic and lymphoid tissue cells are 
revealed by immunoperoxidase method. Pathol., Res. Pract. 169, 287-297.

Pirttila, T., Mehta, P.D., Frey, H., Wisniewski, H.M., 1994. $\alpha$-1-Antichymotrypsin and IL-1 $\beta$ are not increased in CSF or serum in Alzheimer's disease. Neurobiol. Aging 15, 313-317.

Sheng, J.G., Griffin, W.S., Royston, M.C., Mrak, R.E., 1998. Distribution of Interleukin-1-immunoreactive microglia in cerebral cortical layers: implication for neuritic plaque formation in Alzheimer's disease. Neuropathol. Appl. Neurobiol. 24, 278-283.

Singh, V.K., Guthikonda, P., 1997. Circulating cytokines in Alzheimer's disease. J. Psychiatr. Res. 31, 657-660.

Strauss, S., Bauer, J., Ganter, U., Jonas, U., Berger, M., Volk, B., 1992. Detection of interleukin- 6 and $\alpha$-2-macroglobulin immunoreactivity in cortex and hippocampus of Alzheimer's disease patients. Lab. Invest. 66, 223-230.
Travis, J., Salvelsen, G.S., 1983. Human plasma proteinase inhibitors. Annu. Rev. Biochem. 52, 655-709.

Van Duijn, C.M., Hofman, A., Nagelkerken, L., 1990. Serum levels of interleukin-6 are not elevated in patients with Alzheimer's disease. Neurosci. Lett. 108, 350-354.

Xiao, E., Xia, L., Ferin, M., Wardlaw, S.L., 1999. Intracerebroventricular injection of interleukin-1 stimulates the release of high levels of interleukin-6 and interleukin-1-receptor antagonist into the peripheral blood in the primate. J. Neuroimmunol. 97, 70-76.

Yamin, R., Malgeri, E.G., Sloane, J.A., McGraw, W.T., Abraham, C.R., 1999. Metalloendopeptidase EC 3.4.24.15 is necessary for Alzheimer's amyloid- $\beta$ peptide degradation. J. Biol. Chem. 274, 18777-18784. 